\title{
A CONTRIBUIÇÃO DE HELEIETH SAFFIOTI PARA A ANÁLISE DO BRASIL: gênero importa para a formação social?
}

\author{
Daniele Motta*
}

\begin{abstract}
Este artigo tem o objetivo de questionar se as ideias desenvolvidas por Heleieth Saffioti podem ser lidas como uma contribuição para a análise da Formação Social do Brasil. Dessa forma, apresenta a leitura da autora sobre as relações patriarcais existentes no país explicitando que a formação da sociedade brasileira se deu impregnada por este tipo de dominação e trazendo para esta análise a perspectiva das mulheres. Estabelecemos um diálogo com Florestan Fernandes, a partir da ideia das reminiscências de relações sociais do "passado no presente". Por fim, avançando no que entendemos como o salto teórico-metodológico da autora, fazemos uma exposição sobre sua contribuição da leitura do problema de gênero na sociedade brasileira, com suas formulações sobre o nó (gênero, raça/etnia e classe) fundamental para a compreensão das relações na sociedade capitalista contemporânea.

Palavras-chave: Heleieth Saffioti. Patriarcado. Formação social. Nó. Capitalismo.
\end{abstract}

\section{INTRODUÇÃO}

A tradição do pensamento social brasileiro é marcada por ser majoritariamente masculina, quantas mulheres são lembradas? Quais obras clássicas discutem a presença e o papel das mulheres na sociedade brasileira? Nos últimos anos assistimos a uma ampliação do interesse pelo pensamento das mulheres e o surgimento de uma epistemologia feminista, que trouxe à tona uma infinidade de autoras que refletem sobre a sociedade brasileira, evidenciando as desigualdades de gênero a partir da perspectiva e das experiências das mulheres. Dessa forma, ficou explícita a necessidade da teoria social refletir sobre as diferentes relações sociais (como as de gênero, classe e raça) e suas imbricações. Trazendo esse debate para o tema da formação brasileira, defendemos que Heleieth Saffioti deveria compor o rol de pensadores sociais brasileiros, pois, a sua obra

* Instituto Federal de Educação, Ciência e Tecnologia de São Paulo (IFSP)

Avenida Doutor Ênio Pires de Camargo, 2971. São João Batista. Cep: 13360-000. Capivari - São Paulo - Brasil. daniele.motta@ifsp.edu.br

https://orcid.org/0000-0002-7296-3688 explicita a importância de um debate sobre as mulheres no capitalismo brasileiro, com uma interpretação inovadora e original. Mas o que deve fazer um autor/autora entrar para esse rol?

Heleieth Saffioti faz um diálogo entre a acepção feminista do patriarcado, a partir da leitura sobre a dominação das mulheres pelos homens, e as interpretações do pensamento social brasileiro. A autora apresenta mudanças nas suas leituras sobre a dominação patriarcal, revelando seu pensamento em movimento constante com os diálogos teóricos que travava e o contexto social e político que enfrentava. A autora vem de uma família humilde do interior de São Paulo, e teve que ir morar longe de seus pais para estudar na capital, onde se formou como Socióloga pela Universidade de São Paulo (USP) em 1960. Mesmo em plena ditadura militar, a autora manteve sua convicção marxista e estimulou a difusão das categorias de Marx através das análises que fazia, com destaque para o livro "A Mulher na Sociedade de Classes", publicada no ápice da repressão ditatorial no país. Resistiu ao regime ditatorial, publicando suas pesquisas sem abrir mão de suas convicções. 
A autora dedicou uma vida à pesquisa, debruçando-se sobre o tema das desigualdades de gênero, e para isso analisou as profissões mais feminizadas no país, como as empregadas domésticas, professoras primárias e trabalhadoras da indústria têxtil. Sua vinculação ao marxismo fez com que se voltasse durante boa parte de sua vida ao estudo das relações de trabalho, buscando compreender a exploração capitalista na vida das mulheres, e especificamente na vida das mulheres moradoras de países periféricos. Inicia a sua pesquisa acadêmica já inaugurando uma tradição: olhar para as mulheres como sujeitas da história. Só essa constatação já seria suficiente para situar uma nova leitura sobre a formação social do Brasil, entretanto, Heleieth ainda dialoga diretamente com os autores clássicos $^{1}$ da formação brasileira e utiliza noções consagradas para a análise da situação das mulheres. Em seu primeiro livro, "A Mulher na Sociedade de Classes: Mito e Realidade" (1969) a autora dedica a parte II à análise da "Evolução da condição da mulher no Brasil”. ${ }^{2}$

Entretanto, o diálogo da autora não se dá apenas com o pensamento social brasileiro. Heleieth trava um debate intenso com os clássicos da sociologia, principalmente Marx - a quem se vincula teoricamente - e além de grandes nomes do marxismo dialoga com a antropologia, a ciência política, a psicanálise e a teoria feminista. Sua leitura sobre o Brasil, ancorada na experiência das mulheres, está ชิ em constante movimento, sofrendo alterações C conforme avança nas suas pesquisas. A autora põe em evidência o fato de que transitamos para o moderno, o modo capitalista de produfi ção, sem romper com o tradicional, representa$\dot{2}$ do pelas relações patriarcais. Dessa forma a auले tora nos leva a crer que a análise das relações $\vec{i}$ entre homens e mulheres é parte fundamental para a compreensão do autoritarismo no país. Daí a relevância do tratamento da questão de gênero para a compreensão da democracia, re-

${ }^{1}$ Caio Prado Jr ([1942] 2000), Gilberto Freyre([1933]2004), Florestan Fernandes.

${ }^{2}$ Cf. Saffioti ([1969a] 2013). fletindo sobre suas possibilidades e limites.

Partindo da ideia de que Heleieth Saffioti oferece uma contribuição ao pensamento social brasileiro e deveria estar presente em bibliografias das disciplinas sobre o tema, bem como ser considerada nas reflexões sobre as possibilidades democráticas no Brasil, este texto a situa como herdeira da Escola Paulista de Sociologia. Para tal, buscamos apresentar de forma breve a acepção da autora sobre a herança patriarcal e estabelecer um diálogo com Florestan Fernandes a partir da ideia da relação do tradicional com o moderno e da relação entre a diversidade e a desigualdade. Uma característica dos estudos realizados pela autora é o comprometimento com a análise empírica, o que fez em vários trabalhos que envolveram um mergulho no campo de pesquisa, uma vez que buscava desvendar os lugares ocupados pelas mulheres na sociedade brasileira. Em seguida, será discutido o que consideramos o salto teórico-metodológico da autora a partir da ideia do imbricamento das relações de gênero, raça/etnia e classe como resultado de seu diálogo intenso com a teoria feminista.

Por fim, a intenção é refletir em que medida as formulações da autora, tratada como uma clássica da sociologia brasileira, podem iluminar nossas reflexões para a compreensão da sociedade brasileira até os dias atuais.

\section{HELEIETH SAFFIOTI: uma pensa- dora social do Brasil?}

Sob a perspectiva da formação da sociedade capitalista, a colocação do problema das mulheres demonstra sua importância para a análise da sociedade como um todo. Ainda que Heleieth Saffioti perceba as especificidades da questão de gênero, não a trata de forma autônoma; esta é uma questão metodológica crucial para o entendimento da sua sociologia, inclusive, apontada por Antonio Candido no prefácio do seu primeiro livro: 
O grande mérito da autora foi não separar o problema da mulher dos problemas gerais da sociedade, mostrando como formigaram racionalizações ideológicas aliadas à estrutura e às formas de dominação (CANDIDO, [1969] 2013 p. 28).

A autora coloca a questão de gênero diretamente associada com a formação da sociedade capitalista e das classes sociais no Brasil, tratando-a como um elemento essencial para pensarmos a formação social. Por isso, para tratar dos problemas que acometem as mulheres é preciso pensá-los junto com o processo de modernização do país. Destacaremos da análise de Heleieth algumas questões que sua pesquisa sobre o emprego doméstico suscitou. Não iremos analisar a categoria de trabalhadoras empregadas domésticas, mas apontar as formulações que a autora, a partir desse estudo, faz sobre a relação entre formação social e modo de produção, questionando as relações de mercado tipicamente capitalistas e as desigualdades de competição no Brasil.

Suas análises sobre as possibilidades e dificuldades de inserção das mulheres nas instituições sociais modernas, principalmente no mercado de trabalho, levam em conta o processo de desenvolvimento do capitalismo, mostrando que a problemática de gênero é parte essencial da questão democrática e da formação do capitalismo no Brasil. Entendemos Heleieth Saffioti como tributária do pensamento Uspiano, mais especificamente da leitura em torno da cadeira de sociologia I, liderada por Florestan Fernandes, orientador de sua tese de livre docência. O fato de ter estudado na USP e sido orientada por Florestan transparece nas suas formulações. Isso fica evidente em "A Mulher na Sociedade de Classes: Mito e realidade”, quando parafraseia o autor:

Se, todavia, o desejo de compreender a problemática feminina nas sociedades de classes e de vislumbrar as vias de sua superação interferir negativamente nas interpretações aqui realizadas, poder-se-ia dizer, parafraseando Florestan Fernandes, que tantos já erraram por motivos diferentes, deformando e detratando a mulher, que não haveria mal maior em tal compensação (Saffioti, [1969A] 2013, p. 49).
Heleieth é herdeira de uma agenda de pesquisa que visou compreender a relação entre a diversidade do povo brasileiro olhando, sobretudo, as sujeitas que estão à margem do processo social, em relação aos aspectos da desigualdade. Se Florestan Fernandes escreveu a partir da análise da população negra, Heleieth Saffioti desvelava tal relação a partir do estudo sobre as mulheres, o que torna possível perceber algumas aproximações nas leituras de ambos sobre a interpretação do capitalismo brasileiro. Não queremos com isso afirmar que Saffioti está totalmente vinculada ao pensamento do autor em questão, ou da escola paulista de sociologia, pois, também é possível destacar distanciamentos teóricos e metodológicos.

Tanto Heleieth quanto Florestan em seus estudos sobre a diversidade social estão refletindo a partir da possibilidade de integração ao mercado de trabalho, e chegam a respostas parecidas. Florestan ao final de "Integração do negro na sociedade de classes" (Cf. Fernandes, [1964] 2008) chega à conclusão de que a população negra não foi totalmente integrada, sendo alijada do processo de modernização. Heleieth, por outros caminhos, também percebe a marginalização das mulheres no desenvolvimento do capitalismo. A diferença crucial entre essas leituras é que Florestan, quando escreveu "Integração do negro na sociedade de classes" parecia acreditar na possibilidade de inclusão no capitalismo, caso fossem adotadas medidas específicas. Já Heleieth nunca pareceu acreditar na possibilidade de as mulheres não ficarem alijadas do mercado de trabalho, e defendeu esse posicionamento em " A Mulher na sociedade de classes" até o final de sua vida. ${ }^{3}$ Nesse sentido, a questão teórico-metodológica se impõe, pois Saffioti sempre se vinculou ao marxismo como forma de explicação social, o que a fez desde o início

${ }^{3}$ Em entrevista a Gonçalves e Branco (2008, p.81) Heleieth reafirma sua tese de 1969: "Esse livro, claro que hoje faria alguns reparos, mas a tese central continua valendo. Muita gente diz: "Ah, mas você diz no livro que à medida que o capitalismo se desenvolve, o mercado se restringe para as mulheres, mas não é isso que acontece. (...) Vai ver onde estão as mulheres! 
de sua pesquisa se aliar a uma leitura na qual a igualdade entre homens e mulheres não caberia no capitalismo.

Queremos destacar dois diálogos importantes que a autora faz com a escola paulista de sociologia: a leitura sobre as relações patriarcais e a permanência do passado no presente (ou a relação entre o arcaico e o moderno).

\section{AS RELAÇÕES PATRIARCAIS}

A análise da família patriarcal marcou a leitura sobre a colonização do Brasil, partindo da ideia de dominação segundo o referencial weberiano, no qual existem três tipos de dominação: carismática, tradicional, legal-racional. ${ }^{4}$ A dominação patriarcal é um tipo de dominação tradicional, sistema de normas baseado na tradição, na autoridade de um senhor, do chefe de família. Ancorados nessa ideia de dominação diversos autores escreveram sobre a família patriarcal como o sustentáculo do Brasil colonial, centrado no senhor de terras como o patriarca que centralizava o poder e a autoridade. Esta seria inclusive uma herança ibérica. E com o olhar sobre esse tema, Heleieth Saffioti vai formular em sua primeira obra a indagação sobre quais seriam os impactos dessa relação na vida das mulheres, apontando inclusive para uma leitura racializada sobre esse processo. ${ }^{5}$ No entanto, ela já apresenta ชิ uma novidade, um caráter cultural a partir da N mística feminina, um diferencial que dá a base para a sua posterior formulação feminista sobre o tema (Modda,2019). Portanto, a leitura fi de Saffioti sobre a família patriarcal presente $\dot{2}$ em "A Mulher na Sociedade de Classes" não ले é só uma leitura sobre a família colonial, pois

${ }^{4}$ Weber (2009) se preocupa em pensar a dominação a partir de sua legitimidade social, como fundamento do poder numa determinada sociedade, levando a população a aceiI tar a obediência a uma determinada ordenação social.

${ }^{5}$ Saffioti (2013) aponta a diferença entre as relações patriarcais para as mulheres negras e brancas na colônia, mostrando que o poder patriarcal era exercido de forma diferente entre as mesmas. Já discutimos essa diferença em outro texto (Cf. Motta, 2018). aponta esta como uma instituição chave fundamental para a manutenção dos mitos sobre as mulheres, que as mantinha (e ainda mantêm) em posição de inferioridade. ${ }^{6}$

Neuma Aguiar (2000) apresenta uma leitura sobre o patriarcado a partir da escola de Florestan Fernandes e inclui, de forma acertada, a contribuição de Heleieth Saffioti. Aguiar afirma que tal leitura aponta para um caráter dúbio do processo de desenvolvimento no Brasil, articulando capitalismo e patriarcado, estamento e classe. Mostra que, em alguma medida, o comportamento do patriarca se manteve nas classes dominantes do país, mesmo com o fim do sistema escravocrata. Esse eixo interpretativo é fundamental para pensarmos a sociedade brasileira em perspectiva, refletindo sobre as continuidades e rupturas dos processos sociais. Segundo Aguiar (2000) um dos eixos que Saffioti utiliza ao desenvolver o tema do patriarcalismo é a situação das mulheres segundo sua racialização, diferenciando o efeito da família patriarcal para as mulheres brancas e negras. Segundo Nascimento,

(...) O Brasil herdou de Portugal a estrutura patriarcal de família e o preço dessa herança foi pago pela mulher negra, não só durante a escravidão. Ainda nos dias de hoje, a mulher negra, por causa da sua condição de pobreza, ausência de status social, e total desamparo, continua a vítima fácil, vulnerável a qualquer agressão sexual do branco (Nascimento, 1978, p. 61).

A análise das relações patriarcais constitui um embrião do que viria a ser o peso do patriarcado em sua obra (Modda,2019) demonstrando o potencial que suas formulações viriam a ter: como uma interpretação sobre as mulheres no capitalismo brasileiro. A autora percebe uma continuidade das relações patriarcais mesmo com o fim da sociedade escravocrata

${ }^{6}$ Foi somente na década de 1970 que as feministas, sobretudo no interior do que ficou conhecido como feminismo radical, passaram a utilizar o patriarcado para denunciar a dominação dos homens sobre as mulheres. Isso também explica o fato de a autora não utilizar esse referencial, pois seu livro foi publicado em 1969 mas foi escrito em 1966. A ideia de patriarcado difundida pelo feminismo será trazida posteriormente por Heleieth Saffioti. 
e senhorial e, sem se furtar ao debate sobre as transformações capitalistas, mostra como patriarcado e capitalismo foram se embrenhando historicamente. Entretanto, o enfoque sobre a vida das mulheres faz com que, ao invés de se tornar uma das autoras clássicas do pensamento social brasileiro, da sociologia brasileira, se torne clássica nos estudos de gênero, já que como ela mesma disse, tratou de um tema da área das perfumarias. ${ }^{7}$ Enquanto pioneira na temática das mulheres, Heleieth teve que combater a ideia de que fazia uma "Sociologia menor”, já que a questão de gênero por muito tempo foi considerada uma leitura específica, de identidade, por isso menos importante para tratar dos "grandes dilemas da sociedade".

Florestan Fernandes, a partir de uma pesquisa empírica sobre a população negra, mostrou como o racismo e o capitalismo se articulam. Desse modo, ambos os autores foram fundamentais para que pudéssemos avançar na teoria social e refletir sobre a relação entre a diversidade social e as desigualdades historicamente construídas. A análise dos aspectos da diversidade brasileira, especificamente gênero e raça, possibilita aos autores ver as permanências de estruturas históricas da sociedade escravocrata e senhorial no desenvolvimento do capitalismo brasileiro e percebem que tais estruturas não atrapalhavam o desenvolvimento do capitalismo, mas permitiam um potencial maior de exploração e dominação. Apontar a integração entre patriarcado, racismo e capitalismo foi fundamental para a compreensão da especificidade da formação brasileira, atentando para os atores sociais presentes na sociedade.

A reflexão que a obra de Saffioti nos traz é: qual o lugar do patriarcado no capitalismo? Ela ousa responder tal questão ao longo de toda a sua vida, concebendo as suas transformações ao longo dos processos históricos, entendendo-os como potencializadores do processo de exploração e dominação que penetra as esferas

${ }^{7}$ A frase irônica "Descobertas da área das perfumarias" dá título a um capítulo do livro "Gênero, Patriarcado e violência” (Cf. Saffioti, [2004] 2015). da vida púbica e privada, estruturando toda a sociedade (Saffioti, [2004] 2015).

\section{O PASSADO NO PRESENTE}

Outro ponto de convergência que buscamos estabelecer entre a autora e o pensamento do seu orientador, Florestan Fernandes, é sobre o processo de mudança social no Brasil, ou melhor, de resistência à mudança social. ${ }^{8} \mathrm{O}$ que aproxima a leitura entre ambos é a influência que têm da tese de Lênin sobre a lei do desenvolvimento desigual do capitalismo. Por caminhos diferentes, pois Heleieth Saffioti vai dedicar sua agenda de pesquisa aos estudos sobre as mulheres, apontando a persistência de relações sociais vinculadas às ordens sociais do passado no processo de transformação capitalista no Brasil, e mostrando a desigualdade de ritmos no desenvolvimento. Isso faz com que ambos percebam o processo de marginalização de grandes contingentes da população brasileira do mercado de trabalho institucionalizado, como já dito anteriormente. Heleieth percebe a mescla das estruturas, segundo ela,

A conservação de sistemas de valores originados em estruturas sociais anteriores permitiria às sociedades de classes utilizar de modo diverso a força de trabalho feminina. (...) na condição das mulheres estavam presentes contradições próprias de formações sociais anteriores e contradições típicas do modo capitalista de produção (Saffioti, 2013, p. 108).

Essa concepção da autora se vincula a uma leitura desta formação, a partir da ideia do capitalismo dependente, próxima aos termos de Florestan. Ainda que sob tal influência, sua análise reflete muito do marxismo e do feminismo, o que a leva a outros caminhos. Por isso, a teoria de Heleieth Saffioti enquanto uma leitura sobre os processos de transformação da sociedade brasileira a partir do feminismo, é também uma crítica à teoria da modernização

${ }^{8}$ Esse é um termo utilizado por Florestan Fernandes. Ainda que Saffioti não use acreditamos que sua teoria em alguma medida corrobora tal leitura. 
no Brasil, tendo em vista que traz a cegueira de gênero presente nas grandes interpretações. ${ }^{9}$

Se por um lado, Florestan traz um aporte sobre a discussão da relação de raça e classe no Brasil, Heleieth o faz com a relação entre gênero e classe..$^{10} \mathrm{O}$ ponto central da discussão de ambos os autores é pensar a herança da sociedade escravocrata e senhorial (racista e patriarcal) na formação da sociedade de classes no Brasil, considerando as diferentes relações sociais e os contextos históricos que interferiram no processo de formação das classes trabalhadoras. Florestan (2008) aponta para a impossibilidade de competição em condições de igualdade a partir da questão racial. Para ele, a transformação na organização do trabalho (de escrava à assalariada) perpetuou com a "inferioridade dos negros", ocasionando um processo de exclusão destes em relação à ordem social. Essa herança colonial é um aspecto da continuidade de elementos "arcaicos" na sociedade brasileira e será uma das esferas típicas do regime de classes no Brasil. Para Florestan, a competição era neutralizada pelos aspectos tradicionais que ainda imperavam:

Operando como um fator de retenção ou de revitalização de privilégios estamentais, a competição se vinculou a processos que inibiram e perturbaram o desenvolvimento do regime de classes ou mantiveram indefinidamente padrões de comportamento e de relação social variavelmente pré e anticapitalistas. (...) incorporada a contextos histórico-so-

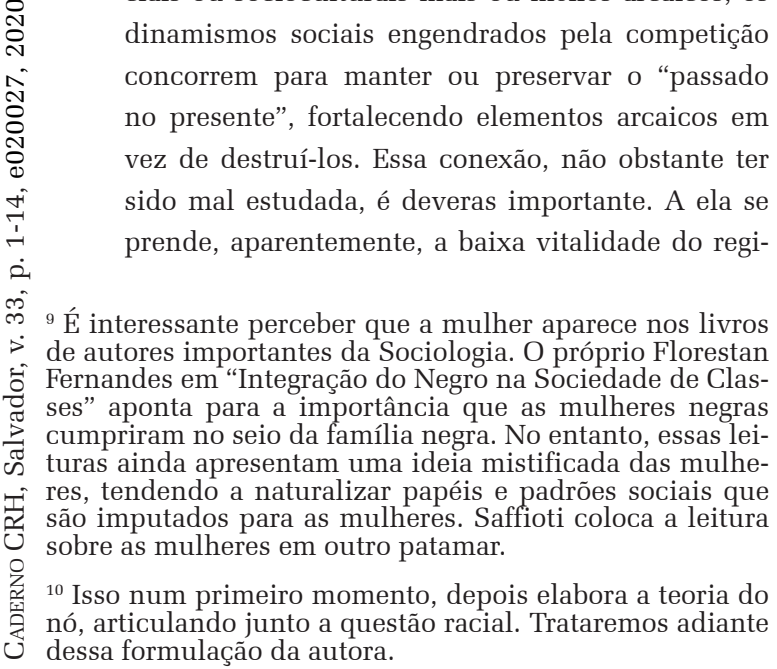

${ }^{10}$ Isso num primeiro momento, depois elabora a teoria do nó, articulando junto a questão racial. Trataremos adiante dessa formulação da autora.

me de classes para pressionar o desenvolvimento econômico capitalista. O horizonte cultural orienta o comportamento econômico capitalista mais para a realização do privilégio que para a conquista de um poder econômico, social e político autônomo, o que explica a identificação com o capitalismo dependente e a persistência de complexos econômicos semicoloniais (Fernandes, [1975] 2006, p. 199).

Já Heleieth percebe a impossibilidade de existirem condições iguais de competição a partir da questão das mulheres:

Já que a estrutura de classes é altamente limitativa das potencialidades humanas, é preciso renovar, constantemente, as crenças nas limitações impostas pelos caracteres naturais de certos contingentes populacionais (contingentes este que pode variar e efetivamente varia segundo as condições sócio-culturais de cada concreção singular da sociedade de classes) como se a ordem social competitiva não se expandisse suficientemente, isto é, como se a liberdade formal não se tornasse concreta e palpável em virtude das desvantagens maiores com que cada um joga no processo de luta pela existência (Saffioti, 1984, p. 60).

A partir de suas pesquisas destacam-se as características de raça e gênero, e o modo como interferem na integração ao regime de classes, colocando tais questões como dilemas da sociedade brasileira, e percebendo sua atuação como um limitador nos processos sociais. Saffioti resume da seguinte maneira:

Os contingentes humanos sobre os quais pesam discriminações sociais são direta e pesadamente afetados pela presença maior ou menor de formas não capitalistas. Os trabalhadores dos setores não capitalistas não usufruem das pequenas vantagens oferecidas pelo capitalismo. Nesse sentido, pode-se afirmar que estão à margem do capitalismo. Estão à margem também do modo de produção capitalista, já que suas atividades, não organizadas nestes termos, caem fora de tal esquema. Contudo, na medida em que tais trabalhadores desempenham tarefas necessárias à reprodução ampliada do capital, não somente estão integrados no sistema capitalista, como permitem a este alcançar uma taxa mais acelerada de acumulação. Assim, na articulação entre as formas capitalistas e não capitalistas de produção, as primeiras beneficiam-se não apenas da exploração de que são objeto os agentes do trabalho subordinado diretamente ao capital, como também da explo- 
ração de que são alvo os agentes do trabalho não-remunerados ou remunerados com renda. Dentre estes, embora haja homens, as mulheres constituem os contingentes quantitativamente mais significativos (Saffioti, 1979, p. 26).

Com base na teoria marxista, a autora faz uma distinção entre modo de produção e formação social. Isso porque cada formação social carrega consigo um modo de produção dominante (no caso, a dominância capitalista) de maneira integrada com relações sociais que não são tipicamente capitalistas. Heleieth percebe isso a partir das suas pesquisas empíricas sobre o trabalho das mulheres, e olhando para o trabalho doméstico no Brasil compreende que as relações de trabalho não tipicamente capitalistas ficam mais evidentes. Sua preocupação é entender esse trabalho, feito por mulheres (de forma remunerada e não remunerada) no interior do desenvolvimento capitalista. Trava um intenso debate sobre o caráter produtivo das empregadas domésticas e as entende como um exército industrial de reserva, estando à disposição do capital em momentos de expansão e de retração. Nas palavras da autora:

a empregada serve ao sistema capitalista, nele integrando-se na medida em que cria as condições para sua plena reprodução. Não podendo usufruir dos benefícios oferecidos por este, pode ser definida como elemento superexplorado das formações sociais dominadas pelo capitalismo (Saffioti, 1979, p. 42-43).

Percebendo a funcionalidade que o emprego doméstico exerce em formações capitalistas periféricas, aponta para a superexploração dos trabalhos feitos pelas mulheres. É interessante perceber que esse debate (da mescla do tradicional com o moderno) é um tema que foi bastante debatido no Brasil até a década de $1960^{11}$. A especificidade da leitura

${ }^{11}$ A tese da dualidade brasileira pautou o debate durante as décadas de 1950 e 1960, entendiam que a economia brasileira dividida em dois setores essenciais: um "atrasado" (produção agrária) e outro "moderno" (produção industrial). Enquanto não houvesse a superação do setor atrasado não haveria a plena modernização do Brasil. Correntes de pensamento importantes da época como o Instituto Superior de Estudos Brasileiros (ISEB) e a Comissão Econômica para a América Latina (CEPAL), além o Partido de Heleieth é o olhar para as mulheres nesse processo, conectando as relações entre gênero e classe, com o pé fincado na realidade histórica social do Brasil, fazendo com que não se vincule a uma visão idealizada/fetichizada do processo capitalista, mais especificamente das mulheres nesse processo, entendendo as permanências e as mudanças na sociedade brasileira. No fundo o que a autora está analisando é como o capitalismo se apropria das relações patriarcais que o antecedem e o faz pensando o patriarcado de maneira geral, como uma forma de dominação e exploração das mulheres no mundo, mas também trazendo-a para a particularidade histórica brasileira.

As desigualdades presentes nas relações raciais e patriarcais da ordem senhorial e escravocrata foram reabsorvidas e redefinidas com o advento do trabalho livre e das novas condições histórico-sociais. Por isso o processo de formação do mercado de trabalho no Brasil, assim como da classe trabalhadora, deve ser entendido paralelamente ao processo de integração das mulheres e da população negra no desenvolvimento capitalista, percebendo o processo de exclusão da população feminina e negra do mercado de trabalho. Para tal análise devemos levar em conta não só as relações de produção e de mercado, mas entender como os critérios de avaliação social foram (e ainda são) largamente apoiados na ideia da "inferioridade" racial e/ou de gênero.

A análise de Heleieth, bem como os dados coletados sobre as trabalhadoras, ainda que possam iluminar as reflexões de hoje, são datados. Se as relações de classe, raça e gênero são dinâmicas e históricas, elas sofrem transformações o tempo todo. Entretanto, compreender seu processo de formação é importante para o entendimento dos pontos de partidas e suas possíveis transformações. Ainda que na Sociologia não se utilize mais o termo relações pré-capitalistas, já que foi preferível qualificar essas relações em outros termos, entendendo-as capitalistas, o debate feito por Heleieth Comunista Brasileiro (PCB). 
Saffioti nos parece consonante com as transformações na organização do trabalho nas últimas décadas. Assistimos a uma mudança nas relações de trabalho que acompanhou as transformações das estruturas produtivas em nível mundial. Esse processo, chamado de reestruturação produtiva, atingiu o Brasil ocasionando o aumento do desemprego, a diminuição do trabalho formal, aumento do trabalho informal, e redução dos salários. As relações de trabalho assalariado e a garantia dos direitos trabalhistas são cada vez menos frequentes no país, no qual as novas formas de contratação através da subcontratação, da contratação de pessoas jurídicas para a realização de atividades exercidas anteriormente por trabalhadores assalariados, eximem os empregadores das obrigações trabalhistas. Ainda que tenha ocorrido a entrada massiva das mulheres no mercado de trabalho (principalmente a partir dos anos 1970), não houve a superação da divisão sexual do trabalho e das desigualdades de gênero, sendo que as mulheres continuam a ocupar trabalhos com altas taxas de informalidade, em condições precárias e instáveis (Cf. Araujo, 2012). As mulheres são parte importante desse mercado informal.

Existe, portanto, no Brasil uma divisão racial e sexual do trabalho que coloca os negros (as) e as mulheres em posição desvantajosa no mercado de trabalho e, sobretudo, as mulheres negras. Dessa forma há um obstáculo จิ de raça e de gênero a ser enfrentado quando $\therefore$ pensamos o acesso aos trabalhos mais bem remunerados e ao próprio mercado de trabalho formal. Com o olhar afiado para as transformađi ções do trabalho a partir das clivagens de gêne$\therefore$ ro e raça Heleieth Saffioti formulou sua teoria ले do enovelamento.

\section{O ENOVELAMENTO DE GÊNERO,} RAÇA/ETNIA E CLASSE

É importante olharmos para o pensamento da autora em movimento, para que possamos perceber as transformações de concepções anteriormente defendidas, e entendermos os avanços teóricos que ela faz. Durante o tempo de sua trajetória, ainda que perceba a importância da análise sobre as relações entre homens e mulheres, a condiciona à questão de classe, sendo esta considerada a mais importante para pensar a sociedade e suas transformações. A autora transformará radicalmente tal visão ao formular a teoria do enovelamento de gênero, raça/etnia e classe (Saffioti, 2004). Isso não significa que o seu pensamento anterior deva ser rechaçado e tomado como menos importante, as concepções e análises feitas anteriormente sobre os temas até aqui expostos, são fundamentais para que a autora formule uma nova perspectiva sobre as questões por ela estudadas. Entendemos que as suas formulações sobre as reminiscências do passado no presente são fundamentais, pois, a permitiram ver como atuam gênero, raça e classe na realidade empírica, articulando as relações morais, culturais, ideológicas e econômicas que já deveriam ser uma relíquia histórica. Nesse sentido, é fundamental situarmos a alteração na sua leitura sobre as relações patriarcais.

Se em "A Mulher na Sociedade de Classes" a autora está fundamentada numa leitura herdada do pensamento social, posteriormente radicaliza sua concepção a partir da leitura feminista do tema, ${ }^{12}$ inclusive, refutando a tese da dominação patriarcal sob influência de Weber, e situando-se no debate feminista. A sua formulação sobre a relação de exploração/dominação como duas faces do mesmo processo, já a afasta da leitura de Weber, para quem as esferas (sociais, econômicas, políticas e culturais) devem ser analisadas de forma separada. Heleieth Saffioti chega à formulação de que exploração e dominação são duas faces do

${ }^{12}$ É importante olhar para a autora e seu contexto. O debate do patriarcado emerge com força a partir dos anos 1970, sobretudo no interior do que ficou conhecido como feminismo radical, passaram a utilizar o patriarcado para denunciar a dominação dos homens sobre as mulheres. Isso também explica o fato de a autora não utilizar esse referencial, pois seu livro foi publicado em 1969, mas foi escrito em 1966. A ideia de patriarcado difundida pelo feminismo será trazida posteriormente por Heleieth Saffioti. 
mesmo processo, entendendo que não existe, de um lado a exploração capitalista, e de outro a dominação patriarcal, uma se alimentando e prescindindo da outra, "não há de um lado dominação patriarcal e, de outro, a exploração capitalista, não existe um processo de dominação separado de outro de exploração" (Saffioti, 2015, p. 138).

Na contramão dos estudos de gênero, a autora não renunciou ao patriarcado como categoria analítica, situando-o não só na esfera privada (da família) mas também na esfera pública (nas instituições sociais). O amadurecimento do conceito de patriarcado que Heleieth aborda, incorporando as leituras feministas na sua análise é, sobretudo, para pensar nessa inter-relação que ela faz da exploração e dominação.

O seu conhecimento sobre o processo da formação social do Brasil, conforme já situamos acima, é fundamental para que ela entenda o patriarcado como uma realidade e uma categoria de análise que não foi superada e deve ser trabalhada para compreensão das relações de exploração/dominação das mulheres, sendo parte estruturante da sociedade, e compondo o que ela denominou de simbiose entre patriarcado-racismo-capitalismo (Saffioti, 1987). Considerando que o estudo do pensamento deva levar em consideração tanto os conceitos e categorias elaboradas quanto o contexto político-social em que se escreve, a obra de Heleieth Saffioti apresenta uma fértil contribuição para a análise articulada de gênero, raça e classe, a autora transformou sua perspectiva analítica, dando importância para a questão de gênero e raça da mesma maneira que para a classe social. Essa mudança é perceptível nos seus textos da década de 1980 e se consolida no "Poder do Macho" (1987). Nesse primeiro livro a autora trabalha com a ideia de simbiose entre racismo-machismo-capitalismo para posteriormente chegar à ideia do nó, que está bem formulada em seu livro "Gênero, Patriarcado e Violência” (2004).

A partir do final da década de 1980 no campo da teoria feminista, as reflexões teóri- cas começaram a pensar uma proposta analítica sobre a origem das diferenças entre homens e mulheres na sociedade e suas articulações, sem privilegiar a análise para uma ou outra relação. Surgiu então uma proposta que trabalhasse com as diferentes categorias - de gênero, raça, classe, sexualidade, geração, nacionalidade - de forma articulada. Além da já citada teoria do Nó de Heleieth Saffioti, conhecemos ao menos outras duas perspectivas que auxiliam na reflexão articulada: a da interseccionalidade e da consubstancialidade. Podemos dizer que existem semelhanças e diferenças entre tais perspectivas: as semelhanças se devem ao fato de ambas surgirem no interior de perspectivas de análises feministas e partirem da deia de não hierarquização de gênero, raça e classe; no entanto, existem diferenças em relação às suas origens e concepções. A interseccionalidade foi cunhada nos Estados Unidos por uma afrojurista, Kimberlé Crenshaw (1989), a partir das demandas de justiça social para as mulheres negras. Pensam a partir de categorias sociais que se cruzam, e se abrem para a possibilidade do entrecruzamento de várias categorias de opressão, como: gênero, religião, nacionalidade, geração, raça, classe etc.

Por outro lado, a perspectiva da consubstancialidade surgiu na França a partir dos debates da sociologia do trabalho, sendo cunhada pela socióloga Daniele Kergoat (2010). A consubstancialidade pensa em termos de relações sociais e entende a imbricação somente a partir das relações que consideram estruturantes, como as relações sociais de sexo, raça e classe; não se abre, portanto para outros pontos de entrada, como a interseccionalidade. ${ }^{13}$ Esse é um ponto da crítica elaborada pelas francesas, que afirmam uma multiplicidade de pontos de entrada que podem levar a uma fragmentação das práticas sociais (Cf. Hirata, 2014; Kergoat, 2016). É importante frisar que, ainda que cada uma a sua maneira, as formas de explicação das relações que eram vistas como menos im(1989), já sobre a Consubstancialidade ver Kergoat (2010). 
portantes - gênero, raça, etnia, nacionalidade, geração etc. -; do campo da cultura e da identidade, passam a ser tratadas no campo da organização social, ganhando novo status.

Podemos dizer que a perspectiva de Heleieth Saffioti, por se situar no campo da sociologia e ter uma base analítica marxista, se aproxima mais da consubstancialidade. No entanto, também cabe colocar que a ideia do nó frouxo desenvolvida por Heleieth (que será apresentada adiante) pode ser diferenciada pois se abre à possibilidade de análise para outras formas de relações sociais, ainda que diretamente relacionada as três relações fundantes (que são as de gênero, raça/etnia e classe). ${ }^{14}$ Torna-se importante situar a tensão entre teoria e movimento social para compreensão da disseminação dessas teorias.

Entre fins da década de 1970 e início da década de 1980 assistimos a uma intensificação na luta dos trabalhadores no Brasil que culminou na constituição do Movimento dos Trabalhadores Rurais Sem Terra (MST), na criação da Central Única dos Trabalhadores (CUT) e do Partido dos Trabalhadores (PT). A reorganização do movimento negro e da luta antirracista no Brasil ocorre nesse mesmo momento de grande articulação nacional pela redemocratização e de grande efervescência no plano internacional de luta antirracista. ${ }^{15} \mathrm{Nes}$ se contexto surgiu o Movimento Negro Unificado $(\mathrm{MNU})^{16} \mathrm{e}$ no interior deste destaca-se จิ Lélia Gonzalez. Segundo Gonzalez (1982) não $\therefore$ dava mais para ignorar essa questão concreta ¿ิ colocada pelo MNU: a articulação entre "raça"

; ${ }^{14}$ Em nossos estudos sobre a obra de Heleieth não encon$\rightarrow$ tramos nenhum diálogo direto com as perspectivas da in-

$\rightarrow$ terseccionalidade ou da consubstancialidade. Ainda que a

$\dot{2}$ autora dialogue com as feministas francesas no seu texto

๗ं em nenhum momento faz referência a perspectiva da con-

$\therefore$ substancialidade.

бิ ${ }^{15} \mathrm{O}$ protesto negro estadunidense no período projetou importantes lideranças na luta pelos direitos civis como MalCom X, e as organizações negras como a dos Panteras Negras influenciaram na criação de um discurso racial mais

Ti radicalizado. Além disso a luta pela libertação dos países

africanos também foram fontes de inspiração para assumir um discurso radicalizado.

${ }^{16}$ O MNU surgiu em 1978 com o nome Movimento Negro Unificado Contra a Discriminação Racial (MNUCDR) e foi rebatizado no ano seguinte. e classe. O MNU foi responsável pela revalorização da consciência negra. É com esse pano de fundo que Heleieth se inspira para alçar seu grande salto teórico-metodológico.

Esse salto não acontece repentinamente, é processual, e suas formulações anteriores são fundamentais para que, ao perceber a continuidade das relações tradicionais (patriarcais, arcaicas, não capitalistas) afirme a importância de outros critérios de classificação, também fundamentais para a manutenção das relações de exploração e dominação, estruturando a sociedade capitalista. Sua intenção é apreender de que forma as características raciais e de gênero operam como marcas sociais que hierarquizam posições e justificam a marginalização de grandes contingentes da população, seja do sistema de produção, seja da estrutura de poder da sociedade brasileira (Saffioti, 2013). Entendemos que sua síntese que melhor explicita esse salto teórico-metodológico é a do nó frouxo. Segundo a autora,

O nó formado por estas três contradições apresenta uma qualidade distinta das determinações que o integram. Não se trata de somar racismo + gênero + classe social, mas de perceber a realidade compósita e nova que resulta dessa fusão (...) uma pessoa não é/ discriminada por ser mulher, trabalhadora e negra. Efetivamente, uma mulher não é duplamente discriminada, porque, além de mulher, é ainda uma trabalhadora assalariada. Ou, ainda, não é triplamente discriminada. Não se trata de variáveis, mas sim de determinações, de qualidades, que tornam a situação destas mulheres muito mais complexa (...) Não se trata do nó górdio nem apertado, mas do nó frouxo, deixando mobilidade para cada uma de suas componentes (Saffioti, 2015, p.133).

Essa imagem do nó frouxo é interessante, pois, ao mesmo tempo que coloca as relações que são fundantes e estruturantes, não as engessa, permite mobilidades. É importante ressaltar que ao tratar essas relações como fundantes não queremos dizer que importam mais que outras relações (ou marcadores de diferença) como a nacionalidade, geração, religiosidade, capacitismo, etc. Em cada contex- 
to é preciso situar as relações de dominação e exploração que afetam a vida das pessoas. No entanto, quando analisadas a partir da inserção na sociedade brasileira, todos os marcadores de diferença passam necessariamente pelas questões de gênero, raça e classe. Isso porque essas são as desigualdades fundantes que estruturam a sociedade brasileira pois se consolidaram historicamente dessa forma. Uma lacuna salta aos olhos quando analisamos o pensamento de Heleieth: o seu silêncio diante do debate feito pelas mulheres negras, que tanto no contexto internacional quando nacional já estavam tratando da mesma temática da articulação de gênero, raça e classe.

Apesar de, às vezes, pouco reconhecida, Heleieth Saffioti é um nome que poderia vir a tomar parte no debate sobre as imbricações que emergem no cenário contemporâneo das Ciências Sociais. Sua teoria do nó, acima apresentada, representa uma leitura das imbricações entre gênero, raça/etnia e classe à brasileira e está em discussão desde a década de 1980, momento de efervescência e surgimento dessa discussão nos movimentos de mulheres negras. Retomar esta autora é um apelo à reflexão a partir de teorias que considerem a realidade brasileira a partir da diversidade do povo, em suas relações com as desigualdades sociais. Nesse sentido, o trabalho da Saffioti é singular e original e a realidade social vem mostrando a importância do aprofundamento de seus textos.

\section{CONSIDERAÇÕES FINAIS}

Se a área de pensamento social supõe diálogos com muitas disciplinas, Heleieth as faz com maestria, trazendo uma reflexão a partir de pesquisas das diversas áreas: história, sociologia, política, antropologia, estudos de gênero, psicanálise etc. Dialoga, dessa forma com várias vertentes teórico-metodológicas. A obra de Heleieth Saffioti traz com êxito a articulação da teoria marxista e feminista e se tor- na imprescindível para quem busca compreender as desigualdades de gênero na sociedade brasileira. Isso posto, conclui-se que a obra de Heleieth deve ser considerada como uma contribuição no pensamento brasileiro, porque é pioneira em trazer o estudo da questão da mulher na sociedade, atualiza a leitura da família patriarcal com uma nova acepção sobre o patriarcado, apresenta a partir da questão de gênero uma importante reflexão sobre as bases do autoritarismo e os limites da democracia no Brasil. Podemos dizer que ela ajuda a pensar um projeto sobre o Brasil, que vincule a mulher como um sujeito social de direitos.

Nos últimos anos os estudos que trabalham com gênero, raça e classe de forma interligada ganharam visibilidade. A disseminação dessa teoria nas universidades e movimentos fez com que ela ganhasse diferentes interpretações. Não queremos aqui entrar nas diferenças entre elas, apenas apontar para a necessidade de enfrentar esse debate como um dos dilemas analíticos para pensarmos o mundo de hoje. Para tal, a autora em foco deveria ser levada em consideração para trazer mais tempero a esse debate, sobretudo, do ponto de vista da realidade brasileira.

A autora também continua atual pelos mitos que aponta, em sua obra de 1969, mostrando como insistem em manter a condição feminina de maneira inferiorizada. Podemos dizer que, pelo menos desde a eleição do atual presidente brasileiro, Jair Bolsonaro, que o caráter patriarcal se desnudou, e os mitos sobre as mulheres e as pautas feministas ganharam corpo em forma de falsas notícias e atuam para impedir que as mulheres avancem para a sua libertação. Heleieth Saffioti já percebia isso como um recurso político, quando afirmou que "Cria-se, então, a imagem da feminista como um monstro que visa a destruir a família e a reduzir os homens à escravidão, numa completa subversão das leis divinas" (Saffioti, 2013, p. 179). Qualquer semelhança com a realidade não é mera coincidência, é mais uma vez as feridas históricas do Brasil se inflamando. 
Hoje com o desenvolvimento das comunicações em tempo real vivemos a ambiguidade de por um lado ter mais acesso a debates e informações de diferentes lugares e perspectivas, de outro vimos a disseminação de ideais autoritários e odiosos por estes mesmos meios. É preciso olhar para essas novas tendências a partir de nossa formação, pois "até mesmo no caso desses novos suportes de comunicação, nunca esteve tão firma a imagem de um presidente-pai, um pater famílias: autoritário e severo diante daqueles que se rebelam; justo e "próximo" pra quem o segue e compartilha suas ideias" (Schwarcz, 2019, p. 63). É o novo e o velho se mesclando mais uma vez.

Nos últimos anos foram implementadas diversas políticas que mexeram com as estruturas históricas das desigualdades, ainda que não tenham corroído sua sustentação. Houve uma ampliação dos direitos trabalhistas das domésticas, as cotas raciais e a ampliação do acesso à universidade, a valorização da produção cultural das periferias, a criação de políticas de igualdade de gênero. Por que será que mexer com essas questões incomodam tanto? Como fazer para que possamos barrar os privilégios de classe, raça e gênero que se perpetuaram na história brasileira? Florestan nos ajuda a compreender que no Brasil "O privilégio é tão ‘justo’ e 'necessário', para as camadas dominantes, e também para suas elites culturais, que as formas mais duras de desigualdade e จิ de crueldade são representadas como algo na․ tural e, até, democrático" (Fernandes, [1972] 2007, p. 294 - grifos do autor). Se a história \& social do Brasil marcou uma continuidade fi das desigualdades entre homens e mulheres, $\dot{2}$ negros e brancos; com a perpetuação das reले lações patriarcais e racistas, a abordagem do $\vec{i}$ nó de Heleieth Saffioti pode ser de grande serventia ainda hoje. No entanto, desatar esse nó que forma a sociedade brasileira é mexer com Fi velhas feridas, com a histórica e contraditória relação entre desigualdade e democracia. Dessa forma, o estudo feito por Heleieth ajuda a entender as diferentes relações sociais que in- terferem na dinâmica social brasileira explicitando a necessidade da luta política por uma transformação nas estruturas históricas trazer a conjunção dos embates de gênero, racial, étnico e de classe.

Reiterar a importância de Saffioti na leitura sobre Brasil é uma forma de sair do apagamento das mulheres na interpretação da sociedade brasileira, tanto como intérpretes, quanto como sujeitas da história, e reafirmar a questão de gênero como um dos pilares para as análises. Recebido para publicação em 20 de julho de 2020
Aprovado em 13 de novembro de 2020

\section{REFERÊNCIAS}

AGUIAR, Neuma. Patriarcado, sociedade e patrimonialismo. Sociedade e Estado. Brasília, v. 15, n. 2, p. 303-329, 2000. Disponível em: http://www.scielo.br/scielo. php?script=sci arttext\&pid $=$ S0102-69922000000200006. Acesso em: 20/08/2018.

ARAUJO, Angela. Informalidade e relações de gênero. In: LEITE, Marcia de Paula; GEORGES, Isabel P. H. (orgs.) Novas configurações do trabalho e economia solidária. Annablume editora, São Paulo: 2012.

CANDIDO, Antonio. Prefácio. In: SAFFIOTI, Heleieth. A mulher na sociedade de classes: mito e realidade. 3a edição. São Paulo: Editora expressão popular, 2013 [1969].

CRENSHAW, Kimberle. Demarginalizing the Intersection of Race and Sex: A Black Feminist Critique of Antidiscrimination Doctrine, Feminist Theory and Antiracist Politics, \&quot; University of Chicago Legal Forum: v. 1989, Article 8, 1989. Disponível em: https:// chicagounbound.uchicago.edu/uclf/vol1989/iss1/8. Acesso em: 9 de Abril de 2020.

FERNANDES, Florestan. A Integração do negro na sociedade de classes: o legado da raça braça, v. 1. $5^{\text {a }} \mathrm{Ed}$. São Paulo: Globo, 2008 [1964].

O negro no mundo dos brancos. $2^{\mathrm{a}}$ edição: São Paulo: Global, 2007 [1972].

A revolução burguesa no Brasil: ensaio de interpretação sociológica. $5^{\mathrm{a}}$ Ed. São Paulo: Globo, 2006 [1975].

FREYRE, Gilberto. Casa-Grande e Senzala: formação da família brasileira sob o regime da economia patriarcal. São Paulo: 49a edição (2004) [1933].

GONÇALVES, Renata; BRANCO, Carolina. Entrevista. Heleieth Saffioti por ela mesma: antecedentes de "A mulher na sociedade de classes". Revista Lutas Sociais, São Paulo, n. 27, p. 70-81, 2011.

GONZALEZ, Lélia. O movimento negro na última década. In: GONZALEZ, L.; HASENBALG, C. Lugar de negro. Rio de Janeiro, Editora Marco Zero Limitada, 1982, p.9-66.

HIRATA, Helena. Gênero, classe e raça: interseccionalidade 
e consubstancialidade das relações sociais. Tempo Social: Revista de Sociologia da USP, São Paulo, v. 26, n.1, p. 6173, 2014.

KERGOAT, Danièle. Dinâmica e consubstancialidade das relações sociais. Novos Estudos Cebrap (86), p. 93-103, março de 2010.

O Cuidado e a imbricação das relações sociais. In: ABREU, Alice Rangel de Paiva; HIRATA, Helena; LOMBARDI, Maria Rosa (Orgs.). Gênero e trabalho no Brasil e na França: perspectivas interseccionais. São Paulo, Boitempo, 2016, p.17-26.

MODDA, Viviane. Revisitando Heleieth Saffioti: a construção de um conceito de Patriarcado. 2019. 95 p. Dissertação (Mestrado em Sociologia) - Programa de PósGraduação em Sociologia da Universidade Federal de São Carlos.

MOTTA, Daniele. Desvendando Heleieth Saffioti. Revista Lutas Sociais, São Paulo, v. 22, n. 40, p.149-160, 2018.

NASCIMENTO, Abdias. O Genocídio do Negro brasileiro: processo de um racismo mascarado. Rio de janeiro: Paz e Terra, 1978.

PRADO JUNIOR, Caio. Formação do Brasil contemporâneo: Colônia. São Paulo: Brasiliense; Publifolha, Coleção Grandes Nomes do Pensamento Brasileiro, 2000 [1942].
SAFFIOTI, Heleieth. Gênero, patriarcado e violência. $2^{\mathrm{a}}$ edição, São Paulo: Expressão popular: Fundação Perseu Abramo, 2015 [2004].

A Mulher na Sociedade de Classes: mito e realidade. Heleieth Saffioti. 3a edição. São Paulo: Editora expressão popular, 2013 [1969].

. O poder do macho. São Paulo: Moderna, 1987.

Mulher Brasileira: opressão e exploração. Achiamé, Rio de Janeiro, 1984.

Emprego doméstico e capitalismo. Avenir editora limitada, Rio de Janeiro, 1979.

Vozes, 1978

Emprego doméstico e capitalismo. Petrópolis,

SCHWARCZ, Lilia. Sobre o autoritarismo brasileiro. São Paulo, Companhia das Letras, 2019.

WEBER, Max. Economia e Sociedade: fundamentos da sociologia compreensiva. 4. ed. Brasília: Editora Universidade de Brasília, 2009 


\section{HELEIETH SAFFIOTTI CONTRIBUTION TO THE \\ ANALYSIS OF BRAZIL: Does gender matter for social formation?}

Daniele Motta
CONTRIBUTION DE HELEIETH SAFFIOTI À

L'ANALYSE DU BRÉSIL: le genre est-il important pour la formation sociale?

Daniele Motta
This article is intended to question whether the ideas developed by Heleieth Saffioti can be read as a contribution to the analysis of the Formation of Brazil. Thus, it presents the author's reading on patriarchal relations in the country, explaining that the formation of Brazilian society was impregnated with patriarchal domination, bringing the perspective of women to this analysis. We established a dialogue with Florestan Fernandes, based on the idea of reminiscences of social relations from the "past in the present". Finally, advancing in what we understand as the theoretical-methodological leap of the author, we make an exposition about her contribution to the reading of the gender trouble in Brazilian society, with her formulations on the knot (gender, race / ethnicity and class) fundamental to the understanding of relationships in contemporary capitalist society.

Keywords: Heleieth Saffioti. Patriarchy. Social formation. Node. Capitalism.
Cet article entend se demander si les idées développées par Heleieth Saffioti peuvent être lues comme une contribution à l'analyse de la formation du Brésil. Ainsi, il présente la lecture de l'auteur sur les relations patriarcales dans le pays, expliquant que la formation de la société brésilienne a été imprégnée de domination patriarcale, apportant la perspective des femmes à cette analyse. Nous avons établi un dialogue avec Florestan Fernandes, basé sur l'idée de réminiscences des relations sociales du "passé au présent". Enfin, en avançant dans ce que nous entendons par saut théorique-méthodologique del'auteur, nous exposons sa contribution à la lecture du problème du genre dans la société brésilienne, avec ses formulations sur le nœud (genre, race/ ethnicité et classe) fondamental compréhension des relations dans la société capitaliste contemporaine.

Mots CLÉs: Heleieth Saffioti. Patriarcat. Formation sociale. Noeud. Capitalisme.

Daniele Motta - Doutora em Ciências Sociais pela Universidade Estadual de Campinas. Integra o Núcleo de Estudos Heleieth Saffioti: gênero, sexualidades, feminismos, da Universidade Federal de São Paulo, desenvolvendo pesquisas na área de pensamento social brasileiro, gênero e interseccionalidades. Professora Substituta de Sociologia do IFSP - campus de Capivari. Publicações recentes: $O$ dilema das desigualdades frente ao marxismo. In: Os desafios do feminismo marxista na atualidade / Danilo Enrico Martuscelli (org.) - 1. ed. Chapecó, Coleção marxismo21, 2020; Desvendando Heleieth Saffioti. In: Revista Lutas Sociais, v. 22, n. 40, 2018; Do universal ao específico: entrelaçando gênero, raça e classe. In: Cadernos Cemarx, n. 11, Campinas, 2018; A originalidade de Heleieth Saffioti na análise crítica da mulher na sociedade capitalista no Brasil. (co-autoria com Elaine Bezerra). In: Anais do IX Colóquio Internacional Marx e Engels, Campinas, 2018. 